\title{
13. Subtitling and dubbing in telecinematic text
}

\author{
Marie-Noëlle Guillot
}

\begin{abstract}
This contribution focuses on audiovisual translation (AVT) and the relatively neglected domain of subtitling and dubbing in telecinematic text from a pragmatic perspective, in effect cross-cultural by dint of the interlingual transfer involved. AVT language is fictional language, with the additional twist of mediating text and meaning across languages and cultures in a multimodal context in which source and target remain intertextually linked. The article provides an overview of the main aspects involved in engaging with AVT from this perspective, and of the two main domains in which pragmatics has been represented within it: narrative aspects and characterization, and communicative practices in their interlingual representations. Audience design, stance, voice, versimilitude are key features for AVT in the pragmatics of its fiction, as in fiction in general. They are uniquely modulated in AVT by the idiosyncratic features of translation modalities, in ways which are yet to be fully mapped out.
\end{abstract}

\section{Introduction}

This chapter deals with subtitling and dubbing in telecinematic text, and their singularities for pragmatics research as so-called 'constrained' translation modalities, i.e. modulated by language-external medium related factors (see next section). Research in the pragmatics of telecinematic discourse requires a multimodal multisemiotic approach which pays heed to co-occuring modes of expression that trigger pragmatic inference. One component in this interaction is verbal language, with its own pragmatic specificities and narratively-driven representations of naturally occurring speech in dialogues. With foreign films subtitled or dubbed into other languages, there is an added level of complexity that makes interplays of meaning making resources and their collective pragmatic import even more intricate.

Subtitled and dubbed dialogue texts are fictions twice over, and are de facto cross-cultural from a pragmatics standpoint Through interlingual transfer, they take make-believe one step beyond the make-believe of the dialogues they represent for audiences with no or limited familiarity with the source languages of original films. This is their main common feature. They are otherwise quite distinct, both in their characteristics as representational mediums and in the strategies they can each deploy to achieve representation within the multimodal film context. These features make them complex to 
study, yet particularly interesting for pragmatics, a perspective neglected until recently in audiovisual translation (henceforth AVT), the generic term used in the field to refer to the range of practices relating to language transfer in audiovisual products.

AVT studies itself is a relatively new discipline. A forum on AVT and language transfer in celebration of the 100th anniversary of cinema set an early milestone in 1995 (Gambier 2003). There were many challenges to confront in these early days, such as mapping out the field, developing research paradigms and adapting methodologies to its specificities within the broader fields of Translation Studies and Film Studies. AVT research is now maturing into a discipline in its own right (Díaz Cintas and Neves 2015; Pérez-González 2014: 92), with interdisciplinary input from a range of other domains, from IT for technical aspects to cognitive sciences, psychology, sociology or neurology. ${ }^{1}$ Pragmatics itself has only recently begun to receive more focused explicit attention and develop greater visibility within AVT research. It is of course present implicitly in all studies that consider aspects and features of interlingual transfer, as pragmatics in the general sense in which it is understood for the purpose of this paper, i.e. how language is used in social contexts and how participants in communicative situations generate (convey and manipulate) meaning. In pragmatics research, the presence of AVT is almost negligible: there are few publications on the topic in main pragmatics journals (two in the Journal of Pragmatics since 1995, for example).

Subtitling and dubbing are accessibility practices. They give viewers access to film dialogues and other narratively relevant textual matter of telecinematic discourse in languages of which they have no or limited knowledge, and the opportunity to make sense of, and respond to, AV cultural products which they would not otherwise be able to decode linguistically. They are also creative media in their own right, both in the kinds of fansubbing/dubbing amateur practices which have developed at an extraordinary rate with digitization since the mid-80s and are now ubiquitous on online platforms and in mainstream practices, despite the pressures of conforming to the normative pressures of the industry in mainstream audiovisual translation and guidelines (e.g. time and space; see Section 2). Creative solutions are required to safeguard the coherence of the narrative, while accommodating the specificities of AV modalities/subtitling and dubbing, and to cope with linguistic and cultural mismapping across languages. The enduring link with the source text still present, intertextually at least, through what is seen and heard is a further difficulty.

\footnotetext{
${ }^{1}$ Pérez González (2014) identifies the following models and approaches as contributing to AVT research in his cutting edge volume on theories, methods and approaches in AVT: psycholinguistic, cognitive, neurolinguistics, pragmatics for process models; shift-based and corpus driven for comparative models; systems and norm-based, discourse and ideological for causal models (Ch. 4, 91-139).
} 
The tension between accessibility and creativity has been an everpresent theme in AVT research. It has received increasing prominence and momentum from norm-defying fansubbing/dubbing amateur transformational approaches and their challenge to representational 'fidelity'. It is an overarching theme from the perspective on the pragmatics of fiction in relation to medium constraints, questions of audience design and linguistic and cultural alignement. These questions and aspects are documented in this chapter primarily by reference to mainstream film practices in the first instance.

The opening part of this chapter in Section 2 provides a brief overview of the main features and issues of subtitling and dubbing and work in AVT research, in order to contextualize the two main dimensions of AVT and the pragmatics of fiction considered susbsequently: narrative and characterization in Section 3; and interlingual representations of communicative practices in Section 4. The conclusion in Section 5 considers a way forward for research, in light of the mounting public prominence and influence of the fansubbing/dubbing crowdsourcing amateur practices signposted above and also outlined in Section 2.

\section{Aspects and features of AVT}

There is a wealth of material recapitulating features of film subtitling and dubbing which, at regular intervals, take stock of how they keep pace with the extraordinary technological developments of the last 15 years, and unprecedented global dissemination of cultural products on a range of platforms (mobile/hand held devices, catch up or on-demand television, etc.). Key work includes benchmark handbooks on subtitling (Díaz Cintas and Remael 2007), dubbing (Chaume 2012), and audiovisual theories, methods and issues (Pérez González 2014). Routine updates have also been provided by regular AVT commentators (e.g. Chaume, Chiaro, Díaz Cintas, Gambier, Pérez González, Remael) in special AVT issues of research journals or translation studies handbooks, such as the (2003) landmark special issue of The Translator on Screen Translation, Millán-Varela and Bartrina's (2013) Handbook of Translation Studies with articles on the state of AVT studies in general (Gambier), subtitling (Díaz Cintas), dubbing (Chaume), a (2016) Target issue on AVT and its theoretical and methodological challenges edited by Ramos Pinto and Gambier with contributions ranging from multimodal approaches (Taylor) to language policy and planning in AVT (O'Sullivan), and Pérez González' (fc. 2017) Handbook of Audiovisual Translation with 40 chapters covering all aspects of this new field (see also Chiaro 2009; Díaz Cintas 2010; Gottlieb 1998; O’Connell 2007; Pérez-González 2009; Remael 2010; Taylor 2013; Yau 2014 among others). Readers are referred to these sources for fuller accounts of the main features, issues and strategies of 
subtitling and dubbing. They are, however, briefly recapitulated below to contextualise subsequent sections.

Engagement with pragmatic concerns in AVT research has, until recently, been largely implicit and tied in with feasibility and practicability issues: how to deal with culture specific reference, register and the sociocultural diversity of language varieties, orality and naturalness, etc. These questions are discussed in view of linguistic considerations (extent/limits of linguistic and cultural mapping, for example), but in view also significantly on technical factors referred to as 'constrainsts' in most of the literature, and of modality features. Subtitling involves a shift from speech to writing, dubbing does not. Each thus mediates telecinematic discourse interlingually in its own distinctive ways.

For subtitling, the central concern is to "render different types of speech in two lines of concise and intelligible writing with a minimal loss of informative content", ${ }^{2}$ while simultaneously conveying register, non-standard language, linguistic idiosyncracies, paralinguistic and interactional features of dialogue in writing, all in synchrony with the filmic image and dialogue (Remael 2003: 226). Remael's concise account encapsulates the main features of subtitling identified in mainstream practices: space and time constraints, and the resulting main strategy - reduction (through omission, condensation, synthesis, modulation, etc.). Readibility is a priority, and is also contingent from the normative perspective of mainstream practices on syntactic and lexical simplification: the object is to keep the cognitive demands of processing fragmented text sequentially manageable, since subtitles appear one at a time, while also responding to visual and aural signs, and to the multimodality of the film medium, a third core aspect. The resulting language choices and strategies make subtitling linguistically, pragmatically and socioculturally distinctive.

For dubbing the main concern and strategy drive is synchrony isochrony, lip-synchrony, kinesic synchrony, character synchrony -, i.e. rendering lines of speech into lines of speech of the same duration in the target language, with matching lip movements and mouth articulation, and consonant with characters' body movements, actions and voice. Actors should not be seen to say nothing when dubbing text is heard, or heard to say nothing when their mouths are moving, lip movements from source utterances should as far as possible match the sounds heard in the target, actions should match words (e.g. acquiescence, greetings), and voices voices (males should dub males, females females, children children etc.). As with subtitling, language choices are inevitably affected. Significant adaptations are called for in word order and information flow in order to, for example, align speaker and voice while weaving in the various semiotic codes and creating the

\footnotetext{
${ }^{2}$ Subtitles are normally expected to be one or two lines of 36 to 40 characters at most in mainstream practices, including spaces and punctuation, and shown at the bottom of the screen.
} 
illusion of original dialogue in the target language, and what Chaume (2012: 16) describes as prefabricated orality (see also Dynel, this volume; Bednarek 2010; also Kozloff 2000). These changes likewise indelibly mark the language of dubbing or 'dubbese', the commonly used term that is an index of dubbing's specificities.

These broad differentiating features correlate with preferences for one or the other modality, historically, geographically and culturally, with regards to costs, literacy and exposure to source languages, for example. Pros and cons of one or the other modality have been a staple topic in AVT (see Koolstra et al. 2002, for example). Dubbing has been more prevalent in socalled 'dubbing' countries, with markets large enough to absorb the higher costs of (labour-intensive) dubbing, limited literacy, at least in the early days of cinema, and/or where it was expedient for censorship in its total replacement of original soundtracks (e.g. Italy, Spain) (see e.g. Díaz Cintaz 2012). Subtitling has a niche in contexts with smaller prospective audiences, like Scandinavian countries, which have thrived on its educational value (e.g. for language learning). Advantages and disadvantages are now modulated by the considerable impact of digitization on practices, subtitling in particular, for which the vast community of amateur subtitlers, or fansubbers, has been re-writing the rule books (see below and Section 5). This is a space to watch for research, including pragmatics research.

For pragmatics and the pragmatics of fiction, subtitling and dubbing are of interest in two main respects as meaning making resources:

- $\quad$ as language registers warranting research attention in their own right: this is a relatively recent stance, but has been gaining ground (see, e.g., Pérez González 2007: 8 and Chaume 2004 for early signs, Pavesi and Guillot in Section 4 for more recent developments);

- as a source of data for pragmatics: subtitling and dubbing give a bird's eye view of how language users perceive and represent their communicative practices in a broad range of contexts, which is an increasingly recognised function of fictional text identified in the introduction in this volume (see also Dynel, Ch. 16, this volume). They have from early on been considered valuable educational tools, for language learning and for promoting intercultural awareness (see e.g. Gambier, Caimi and Mariotti 2015; Pavesi 2015; d'Ydewalle and Van de Poe 1999).

Representation cannot be, and is not, literal. This is an inescapable factor that is sometimes lost sight of in AVT discussions, but it is fundamental for research. Representation is the end-product of the unique three-way relationship between naturally occuring speech, fictional representations of dialogues driven by narrative efficiency and audience design, and interlingual representations conveyed through AVT modalities with different meaningmaking capacities as a function of the features outlined above (see also 
Guillot 2106a). Two further aspects that are of particular bearing in this interaction are audience design and cultural a-synchrony (after Manhart 2000).

The first aspect relates to the particular relationship in AVT with audience design and the so-called double layerness of filmic dialogues. These notions are derived from Bell (1984) and Vanoye (1985), the staple references in AVT studies for questions of participation structure in telecinematic discourse (see Messerli, Ch. 2, this volume for more recent models; Bubel 2006, 2008; Bednarek 2010; Dynel 2011; Brock 2015). There are tensions, in AVT practices and in research about AVT practices, between the horizontal diegetic plane of communication between the film characters and the vertical level of interpersonal communication between the film makers and recipients. In dubbing, for example, the drive to achieve synchrony is seen to promote a sentence-by-sentence approach and local intra-turn decisions that do not necessarily pay heed to the overall picture of the narrative (Pérez González 2007 and next section). Focus on the horizontal at the expense of the vertical is pervasive in research, with discussion of decontextualised text fragments at the horizontal level coming in the way of doing justice to the vertically driven situatedness of language choices and local indexing of pragmatic values (see Sections 3 and 4).

The second aspect, cultural a-synchrony, refers to the cultural mismatch between the foreign that is shown and seen on screen (e.g. Italian, Spanish, Japanese, Russian) and the pragmatic expectations and perceptual frames triggered by text in the audiences' own language in subtitling or dubbing (e.g. English and how politeness is enacted in speech acts, conversational routines, etc.). The mismatch is critical from a cross-cultural pragmatics perspective. Like the interaction between the vertical and horizontal dimensions of film dialogues, it is often mentioned but seldom addressed in full (Guillot 2016a). The pragmatic implications as regards communicative practices and their interlingual representations across modalities are taken up in subsequent sections. As regards translation strategy, cultural a-synchrony results in a tussle between adapting the target text to recipients' linguistic and cultural ways, means and expectations or, conversely, keeping recipients engaged with the source text ways and means. This conflict reflects traditional translation studies debates about 'domestication' (or acculturation) vs. 'foreignization' (after Venuti 1995: 1921). In subtitling, with the co-presence of (oral) source and (written) target, the target text can be falsified by reference to its source. With no such residual exposure to the source, dubbing is almost unimpeded in its capacity to adapt to target practices, which is normally the strategy of choice. It is considered a domesticating practice on this count, with subtitling seen as foreignising, though no less liable to being challenged for compliance with target norms or diktats. Nornes, a prominent rebel voice in AVT studies, has been vigorous in exposing subtitling as 'corrupt', i.e. as a practice that "conforms the foreign to the framework of the target language and its cultural codes". He advocates 
instead what he describes as 'abusive' subtitling, that is subtitling that avoids the erasure of difference and seeks to "intensify the interaction between the reader and the foreign" (Nornes 2007: 178; first published 1999). This is a form embodied in amateur practices like fansubbing, in their target-text resistant disregard of normative guidelines. Fansubbing emerged in the 80s as a reaction by fans of Japanese animated films (anime) to the flattening or domestication in US productions of anything linguistically or culturally Japanese. It has defied standard edicts about number of characters and lines, positioning and layout of text on screen, and made creative use of typography (e.g. to convey emotions), colours, animated writing, headnotes with glossing functions (e.g. to explain culture specific references, untranslatable Japanese terms, cultural connotations of objects or actions shown on screen) etc., in an interplay of diegetic subtitles and non-diegetic materials (Hatcher 2005; Kayahara 2005; Díaz Cintas and Muñoz Sánchez 2006; Pérez-González 2006, $2007 \mathrm{~b}, 2014)$. With digitization, amateur practices have grown exponentially, well beyond Japanese fan clubs and perhaps not as experimentally, but just as unconventionally, across many languages and genres, including (cult) TV series mediated by devotees for devotees in languages not catered for by the industry, or to gain/give access to new releases (almost) at the same time as source audiences. Amateur subtitling in this sense provides a challenging counterpoint, for mainstream practices, and for re-assessing mainstream practices in terms of their own in-build creativity and capacity to mean.

This completes this broad contextualisation overview of main AVT features and aspects, and bird's eye view of the complex issues embedded in dealing with AVT and telecinematic discourse from a pragmatics of fiction perspective. These questions are considered in greater detail with reference to two main angles from which pragmatics has been integrated into AVT research and discussion. The first is narrative aspects and characterization, the second is representation of communicative practices.

\section{Narrative aspects and characterization}

Pragmatics' explicit presence in AVT studies is traced back to narrative aspects and characterization, with a few landmark case studies, notably Hatim and Mason's (1997) study of subtitling within a politeness framework (Brown and Levinson 1987), Remael's (2003) analysis of sequential structure and interactive build up in dialogues and their subtitles from a social psychology perspective, Pérez-González's (2007) appraisal of dubbed conversation from a systemic functional perspective, and more recently Desilla's (2012) consideration of implicature in subtitling within a relevance theory framework. Desilla (2012) is one of very few empirical incursions into reception and audience responses. All four studies consider interpersonal dynamics through the vista of different features. These studies cumulatively provide an overview of the main themes related to narrative and 
characterization in AVT, and the complexities of accounting for them. This kind of work is underrepresented in AVT research.

Hatim and Mason's early (1997) study of subtitling focuses on how the interpersonal dynamics between characters is depicted across source dialogues and subtitles in relation to politeness, as an area of meaning identified in Mason's earlier (1989) work as consistently sacrificed in AVT. The main research question is how this depiction may affect characterization and the narrative. The main conclusion is that "subtitling may create a substantially different interpersonal dynamic from that intended" (Hatim and Mason 1997: 89).

Hatim and Mason argue that politeness is underrepresented in this mode of translating. They identify a "systematic loss in subtitling of indicators of interlocutors accommodating to each other's 'face-wants", (Hatim and Mason 1997: 84) that affects how the interpersponal dynamics between characters is depicted. The loss observed is a consequence of related factors: constraints on translation choices and subtitlers' concern to keep coherence in relation to audience design and guarantee readability and connectivity, the impact of inevitable omissions on target audiences, given that the seriousness of FTA is a function of culture, and subject to the variables of the social distance and relative power of speakers and addressee.

In a study of the French film Un coeur en hiver (Sautet 1992), Hatim and Mason (1997) thus contend that the textual encoding of politeness provides a different picture in the target text, across a set of linguistic features of situation management and interpersonal dynamics in scenes showcasing a conflictual verbal relationship, disagreement, attempted reconciliation, challenge. Lexical choice, grammatical choice (pronouns - site of complex negotiations of face $^{3}$ ), sentence form (imperative, interrogative), unfinished utterances, intonation, and ambiguity in reference produce different politeness strategies in the transfer to English. Form and punctuation also play a significant part in producing different politeness strategies in the target language. Examples are shown in extract (1) from Hatim and Mason (1997: 85-86), where the tension between the two characters is observed to undergo a shift. In the scene Camille, a violinist rehearsing a piece for Stéphane, a violin-maker who has improved the sound of the instrument, is seeking to provoke self-effacing and reticent Stéphane. The text on the right shows the subtitles.

\footnotetext{
${ }^{3}$ Pronominal address for languages with a T/V differentiation like French, German, Spanish etc. is a particular conundrum for AVT, particularly when it plays a key role in characterization and narrative. This is the case for the French film Sur mes lèvres (Audiard 2001) (Read my lips in English), for example, in which shifts back and forth between the two forms between the two protaganists underpin the structure of the film and character development, and are critical for the plot. How this is (successfully) handled in the English subtitles for the film through complementary use of features like register shifts and punctuation as cues is discussed in Guillot (2010).
} 
(1) (Sample 5.1 from Hatim and Mason 1997: 71)

\begin{tabular}{|c|c|c|}
\hline Camille - & $\begin{array}{l}\text { Ça vous convient? } \\
\text { [Does that suit you?] }\end{array}$ & Like it? \\
\hline Stéphane - & $\begin{array}{l}\text { Oui, m... } \\
{[\text { Yes, b...] }}\end{array}$ & Yes, but... \\
\hline Camille - & $\begin{array}{l}\text { Dites. } \\
{[\text { Say it }]}\end{array}$ & Go on. \\
\hline Stéphane - & $\begin{array}{l}\text { Vous n'avez pas joué un peu vite? } \\
\text { [Didn't you play rather fast?] }\end{array}$ & You took it a bit fast. \\
\hline Camille - & $\begin{array}{l}\text { Si. Vous voulez l'entrendre à sa } \\
\text { vitesse. } \\
\text { [Yes. You wish to hear it at its } \\
\text { normal pace.] }\end{array}$ & $\begin{array}{l}\text { Yes. You want to he } \\
\text { it at the right tempo? }\end{array}$ \\
\hline Stéphane - & $\begin{array}{l}\text { Oui, si ça ne ... } \\
{[\text { Yes, if it's not ...] }} \\
{[\ldots]}\end{array}$ & If you wouldn't mind. \\
\hline
\end{tabular}

Preference for brevity and readability produce a concision in the target text that in English would cue solidarity and familiarity (minimizing facethreat, claiming common ground), for example; the strategy is at odds with the strategy observed in the source, where the character Camille does nothing to reduce threat to face and be conciliatory (Hatim and Mason 1997: 88).

Remael's (2003) study also applies to subtitling, but with application to the sequential structure of interactions and their interactive build-up. She, too, contends that subtitling affects characterization and narrative. Normed subtitles are found in her case study to enhance but impoverish characterization in films, and in so doing reinforce their core message or theme and underlying ideology, and cut out voices of dissent (Remael 2003: 225): they heighten contrasts and the dominance of main voices, but can in the process censor the voice of more minor characters and blunt nuances in characterization.

Remael's (2003) analysis draws on social psychology, with concepts from conversational analysis (CA), but places a focus on interpersonal and social relations rather than linguistic analysis. The study takes an interactionist approach that subscribes to Bakhtin and his concept of the dialogism of all communication, and pays heed to the double functioning of dialogues referred to in the previous section. Symmetry and assymetry are central concepts, within and outside the sequentially-built text of (context dependent and context renewing) dialogues. Turns, turn series and exchanges are not just dependent on locally generated dialogues for their representation, their structure reflects the dramatic form of the screenplay at large, as noted elsewhere (e.g. Chaume 2004; Pérez-González 2007a). This point is still frequently overlooked in this and other respects in AVT studies.

Remael (2003) considers three interdependent aspects: (1) interpersonal dominance (quantitative, semantic, interactional, strategic, after Linell 1990); (2) the initiative-response (IR) system; (3) verbal and non- 
verbal and visual signs. She concurrently pays heed to the multimodality of dialogues in relation to their narrative functions in film - structuring, narrative-informative and interactional - shown elsewhere to be subject to shifts in film adaptations (Remael 2000). Her case study includes 15 scenes from Mike Leigh's (1996) Secrets \& Lies with Dutch subtitles. Her conclusion is that dominance patterns are confirmed and even enhanced, regardless of where they occur and their function in the film (exposition, development or denouement). Semantic dominance is unchanged, patterns of quantitative dominance are kept as well but are enhanced in about two thirds of cases (8) and weakened in one third (3), the pattern for interactional dominance is reversed in one case, confirmed in four, enhanced in ten (Remael 2003: 235).

A few patterns are shown to emerge from the analysis. The proactive part of turns that keep dialogue and the story going are usually kept, but there are cuts in their retroactive parts, and cuts in deferring questions and in minimal responses, all performing a cohesive function. A further trend identified is that subtitles start to follow their own sequential logic and deviate from the sequentiality of source dialogues more than is required, to the point in places of turning them into monologues. Cohesion is maintained by visual clues and forward film movement and is not overly affected, but cuts can make characters appear more or less friendly or abrupt, for example, and affect characterization. This extends to rewriting and down toning substandard language, which is also a by-product of reduction, as noted in the previous section.

Example (2) from Remael's study illustrates effects of reduction further. The scene refers to the sudden appearance of a half-sister in the character Roxanne's life. Maurice is her mother Cynthia's husband. The text on the right shows the Dutch subtitles.

(2) (Remael 2003: 243-244; Leigh 1997: 92-95)

Roxanne:

Why didn't you tell me, Maurice?

$\underline{\text { ST } 1363}$

Maurice:

I thought you knew.

Waarom ze je me niets?

Roxanne:

You used to tell me everything!

Maurice:

I'm sorry

Roxanne:

Well, you've fuckin' well let

me down

NO SUBTITLTING

Maurice:

Oh, don't say that!

Jij zei me altijd alles.

NO SUBTITLING

ST 1364

Je hebt me verraden.

[You've betrayed me]

- Zeg dat niet!

For Remael, the scene demonstrates how subtitles are shown to give priority to the narratively prominent character (Roxanne). Her aggressive 
traits are considered to be accentuated in the subtitles, where the source dialogue is rendered as a monologue, despite the toning down of the nonstandard swearword. At the same time, the cuts promote the film's views on men and women.

Remael echoes Hatim and Mason in her conclusions. In both studies, reduction, the core strategy for promoting readability with attendant syntactic and lexical adaptations, is the principal feature affecting verbal exchanges in pragmatic terms. In both, it is seen to affect characterization and the narrative that dialogues drive forward, despite the complementary role of visual clues. Reduction does not apply in dubbing to the same extent, but dubbing has its own pragmatic conundrums to contend with.

Pérez-González's (2007) study applies to dubbing, i.e. to AVT in its oral medium and as an oral medium. He considers how interactional naturalness is construed in dialogues and their dubbing. The theoretical objective is of develop an identifiable framework to make sense of potential mismatches between source and dubbed dialogues as regards naturalness, and to inform professional practice. A main conclusion is that translation triggers shifts from appraisal to mood purposes, or telos, with the consequence that spontaneous sounding fragments of original dialogues are occasionaly neutralised by the overall artificiality of the interactional dynamics in the target language (Pérez-González 2007a: 34).

The research is predicated on the observation that authenticity in dialogues is jointly accomplished by the fictional characters through a combination of prefabricated orality and spontaneous-sounding interaction over stretches of conversations. This is in line with input from stylistics, film studies and corpus-based translation. The success of the narrative and characterization-enhancing resources deployed in a film is thus contingent on the build-up of interpersonal alignments through a combination of both. Pérez-González explores how the dialectic between them is handled in translation, and assesses the impact of translators' mediation on the authenticity of translated conversations in relation to the source, thus on charaterization and narrative. His framework draws on Martin's $(1992,2000)$ systemic functional model of the exchange, and maps out the co-construction of interpersonal meaning through talk by coding moves (knowledge-oriented and action-oriented moves) and interpreting various motifs relating to different functions in the model: serial motif (ideational function), orbital and periodic motifs (textual and meta-functions), and prosodic motifs (the latter were introduced by Martin to tackle the relationship between the other three). These moves and motifs are analysed in relation to their telos, or purposes: mood and appraisal.

Pérez-González (2007) confirms that naturalness is sequentially construed by characters, through interplay of mood and appraisal telos: film dialogues are shown to rely heavily on mood telos, and thus to prioritize the transfer of ideational and textual meanings of interaction (mood) at the expense of the interpersonal aspects (appraisal). In their translation, there are 
further shifts from appraisal telos in the source text to mood telos in the target, resulting in spontaneous-sounding fragments in the source being neutralized in the target by artificiality in the interactional dynamics (PérezGonzález 2007a: 34).

Importantly, and in line with the conclusions in the two previous studies reviewed, Pérez-González (2007: 34) ascertains that "naturalness in film dialogue is more amenable to systematic description when analysed over extended stretches of interaction rather than by ascertaining the presence/absence of certain linguistics items within the limits of a single turn or clauses". The tendency to restrict analysis to very short segments of dialogues is pervasive in research in both film theory and dubbing studies, and results in neglect of the sequential dimension of dialogues. From a theoretical perspective, Pérez-González advocates systemic functional models of CA as "the most productive set of tools [...] to gain insights into the interactive build-up of credible or realistic conversational dynamics in pursuit of specific narrative needs" (Pérez-González 2007a: 35). He notes the need for significant streamlining to make analyses more manageable, however.

With these three studies, two of subtitling, one of dubbing, different aspects of interpersonal dynamics and interaction are represented politeness, the sequential structure of interactions and dialogues, and naturalness. All converge in their conclusions that AVT has an impact on characterization and narrative, and converge, too, on the need to pay heed to the vertical dimension of dialogues, in practice, as noted earlier, and in research. Few studies have done so, which is a reflection of the methodological difficulties associated with dealing with full length source and target narratives, developing replicable frameworks of analysis, and collecting full-length film source and target dialogue data in the first place.

The jury is still out on how compelling these conclusions may be overall beyond the realm of case studies, and indeed on the extent to which the phenomena documented affect audience perceptions and responses. Remael provides anecdotal evidence of audiences responding quite differently in two different contexts to their viewing of the Secrets \& Lies, the Mike Leigh film that is the focus of her case study. Empirical studies of audience responses to full-length films rather than individual scenes are very few. Desilla's $(2012,2014)$ work on the comprehension of implicit film dialogue meaning and implicature across cultures is an exception.

Desilla draws on pragmatics, relevance theory and implicature to address a range of research questions and underlying assumptions about her data: Bridget Jones's Diary (2001) and Bridget Jones: The Edge of Reason, (2004) in their full length; and native speaker responses to the original and subtitled version of these films, in English and Greek respectively. She explores the extent to which British and Greek audiences understand implicatures projected by film makers, the extent to which the Greek audience's comprehension of implicatures is similar to that of the British 
viewers, the contribution of non-verbal semiotic resources to implicature comprehension by the two audiences and, relatedly, how implicatures are cross-culturally understood. Her methodology involves multimodal transcription and pragmatic analysis of the 44 instances involving implicature in the data, and empirical testing of implicature comprehension by SL and TL audiences. She concludes that there is differential access to implicature both across and within source and target audience groups, with allusions challenging for source audiences too and confirming that response to films is not uniform. Implicature recovery is significantly smoother for source audiences, but a great deal of subjectivity and creativity is observed in their response. Significantly, she notes that failure to understand allusions intended by film makers does not always prove (completely) detrimental to film comprehension, and enjoyment.

Desilla's examples of how implicatures fulfil comedic and narrative functions, with reference to word play, intertextuality and metaphor, show complex interplays of all filmic resources, which are too complex to account for here. Just by way of a small example, there is in the film a scene that shows Bridget Jones travelling with her male protagonist in an open-top car and is an intertextual reference to a scene in the film To Catch a Thief, in which romantically involved Grace Kelly and Cary Grant are travelling in a convertible, The reference is a pointer to the kinds of observations that underpin Desilla's conclusions. It is reinforced with a verbal clue from Bridget's narration - "suddenly feel like film goddess, in manner of Grace Kelly" - which may or may not trigger recognition of the implied reference. Together the reference and the additional clue add to the narrative texture and humour of the film, in particular for older generations who are more likely to have access to these references, whether from a Greek or English speaking background. But they do not in this instance come in the way of being able to grasp the intended comedic contrast between the romantic elegance and positive outcome evoked and Bridget's self-confessed clumsiness, humble background and less glamourous relationship upshot.

\section{Communicative practices and representation}

We have little research on responses to interlingual representations of communicative practices in films, and know barely anything about the picture of otherness they convey to audiences. Can these representations globally safeguard a link with the linguistic and cultural authenticity of the source? The question is hugely complex in its own terms. It is intimately dependent on description, for which, too, a great deal of work remains to be done.

There has been a growing interest in dealing with AVT from the crosscultural pragmatics perspective that is called for to develop an understanding of the relationship between source and target in the AVT representation of communicative practices within the multimodal film context. The picture is 
still far from clear. Film dialogues arguably provide us with insights in the way communities of language users perceive their own communicative practices. What story do they give when mediated through AVT?

Communicative practices in intralingually mediated telecinematic discourse is the second domain with a pragmatics dimension represented in AVT studies. AVT research in this domain has been largely incidental, subordinated to documenting issues and typologizing strategies for dealing with them, with respect to recurrent concerns: culture specific reference, humour, the representation of sociocultural features like accents and nonstandard language and orality in the shift across languages, and from speech to writing in subtitling. Research from an explicitly acknowledged pragmatics perspective is more recent. It has become a catalyst for work recognizing AVT modalities as meaning-making resources and registers in their own right, otherwise latent in many case studies and flagged sporadically in earlier work (e.g. Chaume 2004; Pérez-González 2007a).

A catalogue of types of topics addressed across both types of study is shown below. It is based on a small-scale survey of work with a cross-cultural pragmatics dimension in main translation studies journals since their inception undertaken as background work for a project on AVT as crosscultural mediation. ${ }^{4}$ These publications feature comparatively few articles on AVT, and fewer still with a pragmatic dimension, stated or otherwise. ${ }^{5}$ Most have come out in the last ten years or so, which is evidence of the mounting interest in the contributions they are making to the field:

- Studies dealing with text features with a degree of implicit engagement with cross-cultural pragmatics encompass work on:

visualised metaphors; deixis; L3 translation strategies; taboo words and AVT censorship; creativity/ideology issues; domestic culture awareness and translators' active choice of creative language; comprehension problems or mistranscriptions; humour translation in

\footnotetext{
${ }^{4}$ AHRC-Funded network project AH/N007026/1 - Tapping the Power of Foreign Language Films: Audiovisual Translation as Cross-cultural Mediation (PI Guillot, Univeristy of East Anglia; Co-I Desilla, University College London; March 2016-September 2017).

${ }^{5}$ Between 2006 and 2015, there have been 13 papers in Jostran with a pragmatics dimension, 13 in Meta, 10 in Perspectives: Studies in Translatology, 3 in The Translator, 1 in Target, 27 explicitly pragmatic in their approach, 13 implicitly. The budding interest in AVT is yet to be in evidence in pragmatics: the Journal of Pragmatics for example has just two (Cuenca 2008; Desilla 2012), Intercultural Pragmatics and Multilingua just one each (Pinto 2010; Petrucci 2012).

Information for edited volumes has not been synthesized yet, but they are an important dissemination vehicle for AVT research and also feature a selection of relevant studies. See Pavesi, Formentally and Ghia (2014) for dubbing in particular, and Díaz Cintas and Neves (2015) for recent additions; also Freddi and Pavesi (2009), Díaz Cintas, Matamala and Neves (2010), Serban, Matamala and Laveur (2011), Bruti and di Giovanni (2012). See also Mubenga's (2015) doctoral study of request and apology speech acts in the subtitling of English of five feature films in French.
} 
subtitling vs dubbing; relationship between the visual and verbal across source/target visually expressed humour on screen; dubbing across genres; clichés and emotions; multilingualism; irony; intertextuality and impact on interpretation.

- Studies with an explicit cross-cultural pragmatics dimension and approach include work on:

pragmatic features, of orality/naturalness in particular (familiarizers like 'man', 'guys', 'buddy', 'dude'; adverbial intensifiers; phrasal verbs; interjections; discourse markers); lexicon; gay terms and identity; non-standard ('F') word into Catalan; speech acts (implicit compliments; advice; greetings); degrees of alignment between source/target fictional dialogue and spontaneous conversation (with application to demonstratives, pronouns); linguistic/cultural representation in pronominal $(\mathrm{T} / \mathrm{V})$ address, in conversational routines; prototypical sequences or communicative events in crime TV series; rewriting/positive spin on domestication; translation process/creativity in dubbing translation; punctuation as an expressive resource in subtitling; pragmatic errors in dubbing [interjections]; creation/perpetuation of stereotypes; choice of high /low variety in diglossic society (asymmetries across English and Italian); implicature; norms; impact of subtitling and dubbing on the perception of films; narrative issues; unidiomatic language.

The lists give an idea of the range of aspects covered. It is also indicative of the piecemeal nature of work to date and need for a more concerted approach to develop dependable critical mass across both types of study.

In the first type of incidentally pragmatic studies, engagement with language in use is a by-product of dealing with translation, heeding the idiosyncracies of AVT modalities and enduring presence of the source, and attendant strain on the ideal of representational fidelity that has permeated mainstream practices:

- how to deal with culture specific reference (or ECR, for extralinguistic culture-bound reference - Pedersen 2007, 2010), relating to sociopolitical or ethnographic entities tied up with culture, history, geography etc. unfamiliar to prospective target audiences; e.g. references in the Harry Potter series to the public school system, perplexing for most foreign audiences);

- how to deal with humour;

- how to deal with language variation (e.g. sociolects, idiolects, nonstandard language - discussed as critical markers of voice and identity in Planchenault 2015 and this volume);

- how to deal with orality. 
All these aspects are more or less an issue as a function of cultural and linguistic specificity and exacerbated in subtitling with the shift to writing. Interlingual transfer strategies range from literal translation to complete recreations, glossing and omissions across all these aspects. ${ }^{6}$

The reduction that was shown to apply to politeness features in the previous section thus extends in subtitling to all non-essential features from a referential point of view: from mitigating features in face threatening acts, as noted in Hatim and Mason (1997 and previous section) to orality features (filled/unfilled pauses, hesitations, discourse markers denoting particular verbal habits, conversational routines like greetings, leave takings, thanking, etc.), all with important functions for characterisation and for representation, as shown in examples below. In dubbing, synchrony-driven local choices, or prefabricated orality relying on set phrases, vocatives etc., more or less calqued, or literally translated, from source to target are likewise a test to linguistic and pragmactic versimilitude. These inevitable adaptations have fed a loss leitmotiv particularly pervasive in studies with short decontextualised text samples or examples handled at the horizontal level, and popularized in public imagination by Coppola's (2003) film Lost in translation. This insistence on loss is arguably miguided, at least to some extent, as the second type of studies now demonstrates.

Studies explicitly pragmatic in their approach have cast a different light on these phenomena, doing greater justice to the expressive potential that AVT modalities can derive from their specificities and laying the ground for reassessing the impact of cultural a-synchrony. There are different takes on these questions all the same: are the encoding adaptations that are an inevitable by-product of modality constraints conducive to misguided perceptions and stereotyping, or is there a capacity in subtitling and dubbing to activate their own interpretative modes, with selected features indexing internally set pragmatic values?

In a study of advice in a corpus of Spanish films with English subtitles, Pinto (2010) observes increased directness in the target text, for example, resulting from recurring deletion of mitigating features and form shifts (questions in the negative offering advice indirectly turn into direct order imperatives, for example). He is, as a consequence, concerned with the stereotyping of Spanish people as rude. There are features other than reduction, however. In studies of the compliment speech act in subtitling and compliments and insults in subtitling and dubbing Bruti (2009a, 2009b) likewise identifies reduction and omission as recurrent strategies in subtitling, and notes a domesticating shift in the focus of compliments, thus cultural asynchrony masking source pragmatic features (performance in English,

${ }^{6}$ For discussion of all these aspects, see Díaz Cintas and Remael (2017); Chaume (2012) for dubbing; for ECRs, see Agost Canós (2004), Gottlieb (2009), Katan (1999/2004), Ramière (2010), Tomaszkiewicz (2001), Wyler 2003 among others; for humour, see Vandaele (2002), Chiaro (2005), Fuentes Luque (2010), Martínez Sierra (2005, 2009), Zabalbeascoa (2003, 2005); for orality, see Chaume (2004), Romero Fresco (2009) etc. 
personal qualities in the Italian rendering, as in e.g. 'That was great' vs 'you were great' [Sei stata grande] (from Tootsie, Bruti 2009a: 232). Significantly, however, she also points to distinctive uses of language, with locally negotiated and contextualised politeness. Her data features a more diverse set of linguistic expressions for compliments than is observed in sociolinguistic research, for example, and she observes a recurrence of some adjectives like 'brilliant', 'terrific', an avoidance of vague ones like 'nice', expliciteness reinforcing visual or paralinguistic features in the source, and translation of overall gist rather than local segments.

Evidence of AVT's distinctiveness as a linguistic medium has been increasing, for both dubbing and subtitling, largely from input from pragmatics-driven work, in case studies and corpus work, the two main methodologies in AVT research.

Pavesi (2009a, 2009b, 2009c, 2014 inter alia) has been a pioneer for dubbing research, with corpus work that underscores dubbing's creativity and the capacity of selected features to convey pragmatic meaning symbolically and non-randomly, with various functions: privileged carriers of orality (2009a), markers of otherness in pronominal address (2009b, 2009c), sites of cross-linguistic variation in demonstratives (2014), for example.

Guillot identifies comparable mimetic processes in case study work for subtitling (in orality, syntax and punctuation, [T/V] pronominal address, greetings and leave takings, telephone exchanges) (Guillot 2007, 2008, 2010, 2012, 2016a, 2016b). As in Bruti (2009a, 2009b), pragmatic situatedness and indexing is observed: subtitles are shown to set up their own conventions for representing verbal routines or setting communicative preferences, and to evolve their own internal pragmatic settings, in fictional language in which standard routines are in fact present only when they have a narrative function to fulfil. When present at all, they are adapted accordingly. Greeting sequences, for example, are observed to vary from extreme stylization to blatant protractedness for narrative effect, when there. They are established early on as occurring in the films studied, ${ }^{7}$ in line with politeness expectations, and are thereafter taken as read and omitted. The greeting terms present in the few narratively significant scenes in which they are kept are shown to be subject to stylized pragmatic indexing. Just two terms are used in the English subtitles from French of Haneke's (2005) film Caché/Hidden, for example, 'Hi' and 'Hello', the latter only on one occasion, where its occurrence corresponds to a dramatic point in the film ("Hello, Yves."). The shift has nothing to do with rapport, but signals instead the seriousness of the situation: it is a preamble for an anguished question about the whereabouts of the caller's son, who disappeared and is presumed to have been with Yves, his school friend, earlier in the day. Pragmatic indexing is also observed in the source dialogues in all three films in the case study. There is not a one-to-

${ }^{7}$ Caché / Hidden (Haneke 2005), Paris (Klapish 2008), Volver (Aldomovar 2006) (see Guillot 2016b). 
one dialogues/subtitling matching of the values assigned to greetings in each which, however, confirms that subtitles evolve their own settings. Bonsignori et al. (2011) make related observations with reference to dubbing, and Bannon (2013) for professional translation practice.

What applies to greetings applies to other types of conversational or politeness routines: 'please' and 'thank you' framings, for example, are often absent in the subtitles for service encounters, as in a market scene in Aldomovar's Vovler, where "Sure." is established earlier on as evidence that politeness is adhered to. There it flags positive orientation to the foregoing exchange and it then does so in subsequent scenes.

Terms of address can likewise be observed to take on internal pragmatic values. In the film Sur mes lèvres referred to earlier (Audiard, 2001), shifts from title+surname to Christian name are shown to work as a mitigating device, in conjunction with punctuation, in face-threatening acts where the standard mitigating features in evidence in the source have been deleted (Guillot 2010, 2016a). Text stylization itself is critical. In subtitling, text is parred down in the extreme, but this is in itself pragmatically significant. The syntactically and lexically stylized form and paractic presentation of subtitles in stand-alone units affiliate them to speech, and cue orality. They produce opportunities for heightened contrasts that may cue register shifts, and with other features like pragmatic indexing, of words, locutions or punctuation, produce text with its own brand of make-believe. ${ }^{8}$

So what is the story told? And where do we go from here? We are a long way away from being in a position empirically to appraise the relationship between source and target varieties of make-believe in telecinematic discourse and the impact of target kinds on recipients' narrative appreciation and perceptions of otherness. This is an important goal for AVT research. But we are clearer that they are varieties or registers in their own right, and it is clear too that looking further into the pragmatics of AVT's fictions is a means to this end.

\section{The story beyond}

The impact of pragmatics on AVT research has been limited and is still largely piecemeal. Case studies and corpus work with a pragmatics stance have given increasing visibility to its relevance in accounting for AVT practices and for their impact on characterization, narrative and the depiction of communicative practices. There are standard methodological weaknesses

\footnotetext{
8 This is in evidence increasingly, including in more recent studies with an incidental pragmatics dimension: studies of dubbing, for example, like Casarini (2012) for Net Lingo; Forchini (2013) for familiarizers; Matamala (2009) for interjections; Romero Fresco (2009) for orality/naturalness; or Ranzato (2010) for dialects; and studies of subtitling, like De Meo (2012) and Longo (2009) for dialects, for example.
} 
that need adressing, theoretical underspecification, underspecification of research questions, generalization on the basis of limited evidence and short decontextualized segments among them. For AVT specifically, they are a function of what research is currently identifying: neglect of the specificities of film language itself, for example, of the multimodal interdependence of resources in producing meaning, micro-level analyses overlooking the vertical plane on which pragmatic indexing and situatedness are contingent. More than anything perhaps, we need more data, combining full-length film dialogues, aligned AVT text encompassing both dubbing and subtitling to be set against corpora of naturally-occurring speech, as in the exemplary but still all too rare examples set in Italy in the Pavia and Forlí corpora (see, e.g., Baños, Bruti and Zanotti 2013; Freddi and Pavesi 2009).

A next critical step will be to harness to the specificities of AVT the research into the pragmatics of fiction accounted for in this volume, on participation structure in telecinematic discourse (Messerli), for example, on stance (Landert), on performed voices and identity (Planchenault), on difficult questions of verisimilitude (Dynel on (im)politeness). Very little of this material has found its way into AVT studies, where it would provide additional methodological tools for building up the robust picture of its practices that AVT as a discipline in its own right is aspiring to. In this it will also benefit from the challenge of unfettered amateur practices that have thrived with the democratization of access to digital technology. What Pérez González describes as the 'demotic' turn in AVT, with consumers-turnedproducers' or 'prosumers' (after Denison 2011) resisting the highly constraining conventions of the industry and cultural standardization, is another landmark. Self-mediated textualities and the transformational translation practices they promote are for him a source of insights into how AVT can be done, as against how the industry wants it done (Pérez González 2014: 233-34). They bring to light audiences' resilience and capacity to adapt to multiple forms of AVT despite the greater cognitive information load, and their appetite for access to the 'otherness' of source cultural and media products ${ }^{9}$. Fansubbing and fandubbing are putting pay to representational fidelity in mainstream practices, freeing them from their normative straightjacket, as they have films already (e.g. in Slumdog Millionaire, with its non-conventional subtitles, the recent UK TV series of Sherlock Holmes with its multiple inner-thought and other visual adjuncts), promoting subjectivity as an alternative option for quality (Pérez González 2012) and providing scope to reassess mainstream practices from the different angle they provide.

\footnotetext{
9 There are other older examples of less standard forms of subtitling or dubbing, like the voice-over used as a cheap alternative to dubbing in some countries like the Middle East and Asia or former Communist states, that willy nilly retain the authenticity of the source. In Poland, for example, a single (normally male) lektor or voice-over narrator whispers his translation over the audible original voices, in a self-effacing style with no attempt to mimic prosody etc. (Szarkowska 2009).
} 


\section{References}

\section{Primary references}

Bridget Jones's Diary 2001 Dir. Sharon Maguire. Screenplay by Andrew Davies, Richard Curtis, Helen Fielding. StudioCanal, Working Title Films, Little Bird.

Bridget Jones: The Edge of Reason 2004 Dir. Beeban Kidron. Screenplay by Andrew Davies, Richard Curtis, Adam Brooks, Helen Fielding. StudioCanal

Miramax Films, Working Title Films, Little Bird Limited.

Caché / Hidden 2005 Dir. Michael Haneke, Screenplay by Michael Haneke. Les Films du Losange.

Lost in translation 2003 Dir. Sofia Coppola. Screenplay by Sofia Coppola. American Zoetrope.

Paris 2008 Dir. Cédric Klapish. Screenplay by Cédric Klapish. Ce qui me meut StudioCanal and StudioCanal Image France 2 Cinéma

Secrets \& Lies 1996 Dir. Mike Leigh. Screenplay by Mike Leigh. Thin Man Films.

Slumdog Millionaire 2008

Dir Dany

Boyle. Screenplay by Simon Beaufoy./ Searchlight Pictures.

Sherlock Holmes 2010, 2012, 2014, special episode $2016 \quad$ Dir.

Mark Gatiss, Steven Moffat. Screenplay by Mark Gatiss, Steven Moffat and Stephen Thompson. BBC and WGBH Boston.

Sur mes lèvres 2001 Dir. Jacques Audiard. Screenplay by Audiard and Tonino Benacquista. Sédif Ciné Pathé image France 2 Cinéma, with Canal+ and CNC.

Un coeur en hiver 1992 Dir. Sautet. Screenplay by Sautet and Fieschi. Volver 2006 Dir. Pedro Aldomovar. Screenplay by Pedro Almodóvar. Almodóvar and Garcia.

\section{Secondary references}

Agost Canós, Rosa 2004 Translation in bilingual contexts. In Pilar Orero (ed.), Topics in Audiovisual Translation, 63-82. Amsterdam: John Benjamins.

Bannon, David 2013 The Elements of Subtitles: A Practical Guide to the Art of Dialogue, Character, Context, Tone and Style in Film and Television Subtilting. Blackstock: Translation Studies Press (Third edition; first edition 2009). 
Baños, Rocío, Bruti, Silvia and Zanotti Serenella (eds.) 2013 Corpus Linguistics and Audiovisual Translation: in Search of an Integrated Approach. Special Issue of Perspectives: Studies in Translatology 21(4). London: Routledge.

Bednarek, Monika 2010 The Language of Fictional Television: Drama and Identity. London: Continuum.

Bell, Alan 1984 Language style as audience design. Language in Society, 13 (2): 145-204.

Bonsignori, Veronica, Bruti, Silvia, Masi, Silvia 2011 Formulae across languages: English greetings, leave-takings and good wishes in dubbed Italian. In: Adriana Şerban, Anna Matamala, and Jean-Marc Lavaur (eds.), Audiovisual translation in close-up: practical and theoretical approaches, 23-44. Bern: Peter Lang.

Brock, Alexander 2015 Participation frameworks and participation in televised sitcom, candid camera and stand-up comedy. In: Marta Dynel and Jan Chovanec (eds.), Participation I public and social media interactions, 27-47. Amsterdam: John Benjamins.

Brown, Penelope, Levison, Stephen 1987 Politeness: some universals in language use. Cambridge: Cambridge University Press.

Bruti, Silvia 2009a The translation of compliments in subtitles. In: Jorge Díaz Cintas (ed.), New Trends in Audiovisual Translation, 226-238. Clevedon: Multilingual Matters.

Bruti, Silvia 2009b Translating compliments and insults in the Pavia Corpus of Film Dialogues: Two sides of the same coin? In: Maria Freddi and Maria Pavesi (eds.), Analysing Audiovisual Dialogue: Linguistic and Translational Insights, 143-163. Bologna: CLUEB.

Bruti Silvia and Di Giovanni Elena (eds) 2012 Audiovisual translation across Europe: An ever-changing Landscape, New trends in Translation Studies 7. Bern: Peter Lang.

Bubel, Claudia 2006 The Linguistic Construction of Character Relations in TV Drama : Doing friendship in Sex and the City. Retrieved from URL: http://scidok.sulb.unisaarland.de/volltexte/2006/598/ (March 2016)

Bubel, Claudia 2008 Film audiences as overhearers. Journal of Pragmatics, 40 (1): 55-71.

Casarini, Alice $2012 \quad$ XOXO: gossip girl and dubbing in the age of 'net lingo. In: Silvia Bruti, and Elena Di Giovanni (eds.), Audiovisual translation across Europe: an ever-changing landscape, New trends in translation studies 7, 59-78. Bern: Peter Lang.

Cuenca, Maria-Joseph2008 Pragmatic markers in contrast: The case of well. Journal of Pragmatics 40 (8): 1373-1391.

De Meo, Mariagrazia 2012 Subtitling dialects: strategies of socio-cultural transfer from Italian into English. In: Silvia Bruti, and Elena Di Giovanni (eds.), Audiovisual translation across Europe: an ever- 
changing landscape, New trends in translation studies 7, 79-96. Bern: Peter Lang.

Chaume, Frederic 2004 Discourse markers in audiovisual translation. Meta 49 (4): 833-855

Chaume, Frederic 2012 Audiovisual Translation: Dubbing. London Routledge.

Chiaro, Delia 2005 Humour, International Journal of Humour Research, Special Issue Humour and Translation, 18 (2).

Chiaro, Delia 2009 Issues in audiovisual translation. In: Jeremy Munday (ed.), The Routledge Companion to Translation Studies, 141-165. London: Routledge.

Denison, Rayna 2011 Anime fandom and the liminal spaces between fan creativity and piracy. International Journal of Cultural Studies 14 (5): 449-466.

Desilla, Louisa 2012 Implicatures in film: construal and functions in Bridget Jones romantic comedies. Journal of Pragmatics 44 (1): 30-5.

Desilla, Louisa 2014 Reading between the lines, seeing beyond the images: An Empirical study on the comprehension of implicit film dialogue meaning across cultures. The Translator 20 (2): 194-214.

Díaz Cintas, Jorge 2010 Subtitling. In the Handbook of Translation Studies volume 1, Yves Gambier and Luc van Doorslaer (eds.), 344349. Amsterdam/Philadelphia: John Benjamins Publishing.

Díaz Cintas, Jorge 2012 The manipulation of Audiovisual Translation. META 57 (2): 279-293.

Díaz Cintas, Jorge 2013 Subtitling: Theory, practice and research. In: Carmen Millán-Varela and Francesca Bartina (eds.), The Routledge Handbook of Translation Studies, London and New York: Routledge, 285-299.

Díaz-Cintas, Jorge and Remael, Aline 2007 Audiovisual

Translation: Subtitling. Manchester: St Jerome.

Díaz Cintas, Jorge, Matamala Anna and Neves, Josélia (eds.) 2010 New Insights into Audiovisual Translation and Media Accessibility: Media for All 2. Amsterdam, New York: Rodopi.

Díaz Cintas, Jorge and Muñoz Sánchez Pablo 2006 Fansubs: Audiovisual translation in an amateur environment. Jostran: The Journal of Specialised Translation 6: 37-52. http://www.jostrans.org/issue06/art_diaz_munoz.php (last accessed on 23 May 2016).

Díaz-Cintas, Jorge and Neves, Josélia (eds.) 2015 Audiovisual Translation: Tacking Stock. Newcastle upon Tyne: Cambridge Scholars Publishing.

d'Ydewalle, Géry and Van de Poe, Marikje 1999 Incidental foreignlanguage acquisition by children watching subtitled television programs. Journal of Psycholinguistic Research 28(3): 227-244. 
Dynel, Marta 2011 'you talking to me?' The viewer as a ratified listener to film discourse. Journal of Pragmatics 43(6): 1628-1644.

Forcini, Pierfranca 2013 A diachronic study of familiarizers ('man', 'guys', 'buddy', 'dude') in movie language. Perspectives: Studies in Translatology 21 (4), 504-525.

Freddi, Maria and Pavesi Maria 2009 Analysing Audiovisual Dialogue: Linguistic and Translational Insights. Bologna: CLUEB

Fuentes Luque, Adrián 2003 "An empirical approach to the reception of AV translated humour. A case study of the Marx Brothers' Duck Soup', The Translator 9(2): 293-306.

Gambier, Yves 2003 Screen transadaptation: Perception and reception. The Translator: Screen Translation 9(2) (Special Issue): 171-189.

Gambier, Yves 2013 The Position of audio-visual studies. In: Carmen Millán-Varela and Francesca Bartrina (eds.), The Routledge Handbook of Translation Studies, 45-59. London: Routledge.

Gambier, Yves, Caimi, Annamaria and Mariotti, Cristina (eds.) 2015 Subtitles and Language Learning: Principles, Strategies and Practical Experiences. Bern: Peter Lang.

Gottlieb, Henrik 1998 Subtitling. In: Mona Baker (ed.), The Routledge Encyclopedia of Translation Studies, 1st edition, 244-248. London and New York: Routledge.

Gottlieb, Henrik 2009 Subtitling against the current: Danish concepts, English minds. In: Jorge Díaz Cintas (ed.), New Trends in Audiovisual Translation, 21-43. Clevedon: Multilingual Matters.

Guillot, Marie-Noëlle 2007 Oral et illusion d'oral: indices d'oralité dans les sous-titres de dialogues de film. META 52 (2), 239-59.

Guillot, Marie-Noëlle 2008 Orality and film subtitling: The riches of punctuation. The Sign Language Translator and Interpreter, 2 (2), 127147.

Guillot, Marie-Noëlle 2010 Film subtitles from a cross-cultural pragmatics perspective: Issues of linguistic and cultural representation. The Translator 16 (1): 67-92.

Guillot Marie-Noëlle 2012 Stylization and representation in subtitles: can less be more? Perspectives Studies in Translatology 20 (4): 479-494.

Guillot, Marie-Noëlle 2016a Cross-cultural pragmatics and audiovisual translation. In Target Special Issue Audiovisual Translation Theoretical and Methodological Challenges 28 (2), Sara Ramos Pinto and Yves Gambier (eds), xxx-xxx.

Guillot, Marie-Noëlle 2016b Communicative rituals and audiovisual translation - representation of otherness in film subtitles. META 61 (3)

Hatcher, Jordan S. 2005 Of Otakus and fansubs: a critical look at anime online in light of current issues in copyright law. SCRIPT-ed 2(4): 514542. http://www2.law.ed.ac.uk/ahrc/script-ed/vol2-4/hatcher.asp (last accessed on 23 May 2016). 
Hatim, Basil and Mason, Ian 1997 The Translator as Communicator. London: Routledge.

Katan David 1999/2004 Translating Cultures: An Introduction for Translators, Interpreters and Mediators, Manchester: St. Jerome Publishing.

Kayahar, Matthew 2005 The digital revolution: DVD technology and the possibilities for Audiovisual Translation Studies. Jostran: The Journal of Specialised Translation 3: 64-74. http://www.jostrans.org/issue03/art_kayahara.php (last accessed on 23 May 2016).

Koolstra, Cees M., Peeters, Allerd L. and Spinhof, Herman 2002 The pros and cons of dubbing and subtitling. European Journal of Communication 17(3): 325-354.

Kozloff, Sarah 2000 Overhearing Film Dialogue. Berkeley: University of California Press.

Leigh, Mike 1997 Secrets \& Lies. London \& Boston: Faber \& Faber.

Linell, Per 1990 The power of dialogue dynamics. In: Ivana Marková and Klaus Foppa (eds.), The Dynamics of Dialogue, 147-77. Hemel Hampstead, Herefordshire: Harvester \& Wheatsheaf.

Longo, Abele 2009 Subtitling the Italian South. In: Jorge Díaz Cintas (ed.), New Trends in Audiovisual Translation, 99-108. Clevedon: Multilingual Matters.

Manhart, Sybille 2000 'When worlds collide': Betrachtungen über fremde Kulturen im filmtranslatorischen Handlungsgefüge. In: Mira Kadric, Klaus Kaindl and Franz Pöchhacker (eds.), Translationwissenschaft: Festschrift für Mary Snell-Hornby zum 60. Geburtstag, 167-181.Tübingen: Stauffenburg Verlag.

Mason, Ian 1989 Speaker meaning and reader meaning: Preserving coherence in screen translating. In R. Kölmel and Jerry Payne (eds), Babel. The Cultural and Linguistic Barriers between Nations, 13-24. Aberdeen: Aberdeen University Press.

Martin, James Robert 1992 English Text: System and Structure. Philadelphia, Amsterdam.

Martin, James Robert 2000 Factoring out exchange. In: Malcolm Coulthard, Janet Cottterill and Frances Rock (eds.), Working with Dialogue, 19-40. Tubingen: Max Niemeyer Verlag.

Martínez Sierra, José 2005 Translating audiovisual humourA case study. Perspectives: Studies in Translatology 13 (4): 289-296.

Martínez Sierra, José 2009 The challenge fo translating humour for dubbing. Some problematical issues. In Foreign Language Movies dubbing vs. subtitling, Angelika Goldstein and Biljana Golubovic (eds.), 129-149. Hamburg: Verlag De. Kovac.

Matamala, Anna 2009 Interjections in original and dubbed sitcoms: a comparison. META 54 (3), 485-502. 
Millán-Varela, Carmen and Bartrina Francesca (eds.) 2013 The Routledge Handbook of Translation Studies, London: Routledge.

Nornes, Abé Mark 1999 For an Abusive Subtitling. Film Quarterly 52 (3): 17-34.

Nornes, Abé Mark 2007 Cinema Babel: Translating Global Cinema. Minneapolis: University of Minnesota Press.

O’Connell, Erin 2007 Screen Translation. In Piotr Kuhiwczak and Karin Littau (eds.), A Companion to Translation Studies, 120-33. Clevedon, Buffalo and Toronto: Multilingual Matters.

O’Sullivan, Carol 2011 Translating Popular Films. Basingstoke: Palgrave Macmillan.

Pavesi, Maria 2009a Dubbing English into Italian: a closer look at the translation of the spoken language. In: Jorge Díaz Cintas (ed.), New Trends in Audiovisual Translation, 197-209. Clevedon: Multilingual Matters.

Pavesi, Maria 2009b Referring to third persons in dubbing: is there a role for source language transfer? In: Maria Freddi and Maria Pavesi (eds), Analysing Audiovisual Dialogue : Linguistic and Translational Insights, 125-142. Bologna: CLUEB.

Pavesi, Maria 2009c Pronouns in film dubbing and the dynamics of audiovisual communication. VIAL - Vigo International Journal of Applied Linguistics 6: 89-107.

Pavesi, Maria 2014 This and That in the language of film dubbing: a corpus-based analysis. Meta 58(1): 107-137.

Pavesi, Maria 2015 From the screen to the viewer-learner. Audiovisual input as a context for second language acquisition. In: Sandra Campagna, Elana Ochse, Virginia Pulcini, Martin Solly (eds), Languaging in and across communities: New voices, new identities. Studies in honour of Giuseppina Cortese, 83-104. Bern: Peter Lang.

Pavesi Maria, Formentelli Maicol and Ghia, Elisa (eds.) 2014 The Languages of Dubbing. Bern: Peter Lang.

Pedersen, Jan 2007 Cultural interchangeability: The effects of substituting cultural references in subtitling. Perspectives: Studies in Translatology, 15 (1): 30-48.

Pedersen, Jan 2010 When do you go for benevolent intervention? How subtitlers determine the need for cultural mediation. In: Jorge Díaz Cintas, Anna Matamala and Joselia Neves (eds), New Insights into Audiovisual Translation and Media Accessibility: Media for All, 123136. Rodopi: Amsterdam.

Pérez-González, Luis 2006 Fansubbing anime: Insights into the butterfly effect of globalisation on Audiovisual Translation. Perspectives: Studies in Translatology 14 (4): 260-77.

Pérez-González, Luis 2007a Appraising dubbed conversation: Systemic functional insights into the construal of naturalness in translated film dialogue. The Translator 13 (1): 1-38. 
Pérez-González, Luis 2007b Intervention in new amateur subtitling cultures: a multimodal account. Linguistica Antverpiensia 6: 67-80.

Pérez-González, Luis 2009 Audiovisual Translation. In: Mona Baker and Gabriela Saldanha (eds), The Routledge Encyclopedia of Translation Studies (second edition), 13-20. London: Routledge.

Pérez-González, Luis 2012 Amateur Subtitling and the Pragmatics of Spectatorial Subjectivity. Language and Intercultural Communication 12(4): 335-353.

Pérez-González, Luis 2014 Audiovisual Translation: Theories, Methods, and Issues. London: Routledge.

Pérez-González, Luis (ed.) 2017 [in preparation] The

Routledge Handbook of Audiovisual Translation Studies. London: Routledge.

Petrucci, Peter 2012 The translation of cinematic discourse and the question of character equivalence in Talk to me. Multilingua 31 (2-3): 231-251.

Pinto, Derrin 2010 Lost in subtitle translations: The case of advice in the English subtitles of Spanish films. Intercultural Pragmatics 7 (2): 257 277.

Planchenault, Gaëlle 2015 Voices in the Media: Performing French Otherness. London: Bloomsbury.

Ramière, Nathalie 2010 Are you 'Lost in Translation' (when watching a foreign film)? Toward an alternative approach to judging audiovisual translation. Australian Journal of French Studies 47(1): 100-115.

Ramos Pinto, Sara and Gambier, Yves 2016 Target Special Issue Audiovisual Translation Theoretical and Methodological Challenges 28 (2).

Ranzato, Irene 2010 Localising Cockney: Translating dialect into Italian. In: Jorge Díaz Cintas, Anna Matamala and Joselia Neves (ed.), New Insights into Audiovisual Translation and Media Accessibility: Media for All 2, 109-122. Amsterdam: Rodopi.

Remael Aline 2003 Mainstream narrative film dialogue and subtitling: A case study of Mike Leigh's Secrets \& Lies (1996). The Translator 9(2): 225-247.

Remael, Aline 2010 Audiovisual translation. In Handbook of Translation Studies volume 1, Yves Gambier and Luc van Doorslaer (eds.), 12-17. Amsterdam/Philadelphia: John Benjamins Publishing.

Romero Fresco, Pablo2009 Naturalness in the Spanish dubbing language: a case of not-so-close Friends. Meta 54: 49-72.

Serban, Adriana, Matamala Anna and Lavaur Jean-Marc (eds.) 2011 Audiovisual Translation in Close-up: Practical and Theoretical Approaches. Bern: Peter Lang.

Szarkowska, Agnieszka 2009 The audiovisual landscape in Poland at the dawn of the $21^{\text {st }}$ century. In: Angelika Goldstein and Biljana Golubovi (eds.) Foreign Language Movies - Dubbing vs. Subtitling, 185-201. Hamburg: Verlag Dr Kova. 
Taylor, Christopher 2013 Multimodality and Audiovisual Translation. In: Yves Gambier and Luc van Doorslaer (eds), Handbook of Translation Studies volume 4, 98-104. Amsterdam/Philadelphia: John Benjamins Publishing.

Tomaszkiewicz, Teresa 2001 Transfert des références culturelles dans les sous-titres filmiques. In: Yves Gambier and Henrik Gottlieb (eds. (Multi)media Translation, 237-247. Amsterdam: John Benjamins.

Vandaele, Jeroen 2002 (Re)Constructing humour: meaing and means. The Translator 8(2), Special Issue on Translating Humour: 149-172.

Vanoye, Francis, 1985 Conversations publiques. In La parole au cinema/Speech in Film Special Issue of Iris 3(1): 99-118.

Venuti, Lawrence 1995 The Translator's invisibility. London: Routledge.

Wyler Lia 2003 Harry Potter for children, teenagers and adults. Meta 48 (1-2): 5-14.

Yau, Wai-Ping2014 Translation and film: Dubbing, subtitling, adaptation and remaking. In: Sandra Bermann and Catherine Porter (eds.), A Companion to Translation Studies, 492-503. Wiley-Blackwell.

Zabalbeascoa, Patrick 2003 Translating Audiovisual Screen Irony. In: Luis Pérez González (ed.), Speaking in Tongues: Languages across Contexts and Users, 305-322. English in the World Series. Valencia: Publicacions de la Universitat de València.

Zabalbeascoa, Patrick 2005 Humour and translation, an interdiscipline. Humor 18 (2): 185-207. 